\title{
Memória e Valor: Desenvolvimento de Embalagens Para Produtos do Engenho Padre Cícero no Cariri Cearense
}

Memory and Value: Packaging Development for Products from Engenho Padre Cícero in Cariri Ceará

FREITAS, Ingrid Nogueira; Graduada em Design de Produto; Universidade Federal do Cariri ingrid_hp_nog@hotmail.com

\section{Resumo}

Este artigo apresenta os resultados do trabalho de conclusão de curso na Universidade Federal do Cariri intitulado "Desenvolvimento de Embalagens Para Produtos do Engenho Padre Cícero". Tem por objetivos criar uma linha de embalagens para as rapaduras e batidas de um dos últimos engenhos ativos no Cariri cearense, ressignificando esses produtos tradicionais para auxiliar em sua sobrevivência na modernidade e constituindo, durante o estudo de caso do projeto, um registro para preservação cultural das casas de produção açucareira da região. Foi utilizada a metodologia da Universidade Autônoma Metropolitana.

Palavras-chave: embalagens; engenho; rapadura.

\begin{abstract}
This article presents the results of the term paper in Universidade Federal do Cariri entitled "Packing Development for Products from Engenho Padre Cícero". Its objectives are creating a packaging line for the rapaduras and batidas of one of the last active mills in Ceará's Cariri, resignifying these traditional products to help its survival in modern times and constituting, during the project case study, a record for cultural preservation of the sugar production houses in the region. The method used was Universidade Autônoma Metropolitana's.
\end{abstract}

Keywords: packaging; mills; rapadura. 


\section{Introdução}

Este artigo apresenta os resultados do trabalho de conclusão de curso intitulado "Desenvolvimento de Embalagens Para Produtos do Engenho Padre Cícero", aprovado pela Universidade Federal do Cariri (UFCA) em 2017 no curso de Design de Produto.

A pesquisa foi realizada em Barbalha, cidade da microrregião do Cariri, localizada no sul do Ceará, que teve nos engenhos um alicerce social. No entanto, devido a diversos fatores tanto sociais quanto econômicos, os engenhos barbalhenses entraram em decadência e atualmente são escassos. Os ainda existentes têm uma grande probabilidade de aderência a métodos de produção modernizados, a fim de sobreviverem na contemporaneidade.

Enquanto os engenhos, em sua forma tradicional, estão desaparecendo, é importante que a população faça registros de seu patrimônio material e imaterial, a fim de não deixar que se perca no tempo uma história importante para a região e para o país. Os dados colhidos durante o estudo de caso para este projeto constituem um registro dos aspectos atuais do Engenho Padre Cícero, dessa forma contribuindo para preservar a memória do funcionamento das casas caririenses de produção açucareira.

Por outro lado, a tradição nem sempre deve ser mantida como em seus primórdios. Os engenhos, mesmo modernizados, continuarão a ser intrínsecos para o Cariri, apesar de a economia regional não ser mais baseada em sua produção. Suas atuais embalagens, porém, não atendem aos requisitos dos órgãos que regulam produtos alimentícios e não atraem o cliente, indo de encontro às principais funções da embalagem citadas pelos estudiosos da área. Sandra Paiva (2007) diz que, assim como as sociedades mudam com frequência seu estilo de vida, também as embalagens precisam se adequar e se reconhecer no contexto de cada época. É assim que, nesse caso, o Design de Embalagens atua como instrumento de ressignificação e valorização de dois dos produtos mais tradicionais da região caririense: a rapadura e a batida.

Desta forma, o projeto aqui apresentado teve como objetivo desenvolver uma linha de embalagens para as rapaduras e batidas do Engenho Padre Cícero, por meio da pesquisa de sua história, investigação da gama de produtos atualmente ali produzidos e ressignificação das embalagens já existentes, de forma a atender às necessidades da estrutura do engenho e de seu público-alvo. Objetiva-se também, durante o estudo de caso, compor um registro para contribuir na preservação cultural ante a modernização.

A metodologia utilizada foi desenvolvida pela Universidade Autônoma Metropolitana (UAM), que foi proposta no texto Contra un Diseño Dependiente: un modelo para la autodeterminación nacional, de Antunaño et al. (1992). Para efeito didático utilizamos a explicação feita por Negrão e Camargo (2008). Nessa metodologia, que é específica para o projeto de embalagens, há cinco etapas: estudo de caso, problema, hipótese, projeto e produção.

\section{Embalagens}

\subsection{Histórico}

As embalagens, inicialmente, eram reutilizáveis e cumpriam apenas as funções primárias de acondicionar ou empacotar. Potes, barris, vidros, jarras e tonéis eram utilizados, esvaziados, limpos e novamente utilizados, ciclo que se repetia até que estivessem gastos demais para que seu uso fosse continuado. Foi apenas por volta de 1800, no século XIX, com o processo de 
conserva de alimentos em vidro de Nicolas Appert, que surgiram as embalagens de uso único. Entre a metade do século XIX e o final da Segunda Guerra Mundial, a indústria descobriu e aprimorou os materiais e novos formatos, produzindo em larga escala e consolidando as embalagens em nosso dia-a-dia.

Com o estabelecimento do Design como profissão, algo ocorrido na Revolução Industrial inglesa, o designer se tornou oficialmente responsável por pensar uma embalagem para cada produto, desde então ocupando-se dos mais diversos aspectos, desde a estrutura e a parte estética até questões mercadológicas.

\subsection{Funções}

Segundo Negrão e Camargo (2008), as funções das embalagens são:

- Proteger e acondicionar - eliminando riscos, sejam naturais ou por ação do homem;

- Transportar - garantindo a integridade do produto inclusive na etapa do transporte que o próprio consumidor realiza;

- Informar e identificar - fornecendo informações para o consumidor e para os órgãos fiscalizadores;

- Promover e vender - atraindo o cliente como uma ferramenta de marketing;

- Formar e consolidar a imagem - diferenciando um produto de seus concorrentes;

- Funcionalidade - auxiliando na aplicação de um produto na vida das pessoas;

- Economizar e valorizar - não apenas reduzindo custos, mas também conferindo ao cliente um "status" pela compra, respeitando questões ambientais, e promovendo o produto no ponto de venda ou em anúncios.

Dada essa multifuncionalidade, os autores afirmam que não há investimento em comunicação que compense mais que a embalagem. Acrescentam que, quando o produto é simples e não há muito espaço para inovação nele mesmo (como é o caso das rapaduras e batidas que são alvo desse projeto), cabe à embalagem a tarefa de renovar sua imagem.

\subsection{Impacto emocional}

Quando o atendimento na maioria das lojas deixou de ser feito por intermédio de um funcionário e passou a ser responsabilidade do próprio cliente (que escolhe sozinho o que deseja, compara preços e qualidade do que vai comprar), a embalagem tornou-se ainda mais determinante, agindo como um tipo de "vendedor silencioso".

É nesse contato direto e quase imediato do comprador com o produto que a embalagem prova sua eficácia: segundo o site da APESCE (Associação Pernambucana de Shopping Centers), numa pesquisa chamada "A Hora Certa de Ativar o Shopper", realizada em 2015 pela Nielsen, descobriu-se que $70 \%$ das decisões de compra acontecem no ponto de venda. Essa primeira impressão, que comumente se trata da visualização da embalagem na prateleira, é o que Donald Norman, no livro Design Emocional (2008), chama de "design visceral" - algo que seria inconsciente, instintivo e determinante.

É dessa ligação com as emoções que vem a necessidade de incluir na embalagem elementos que tenham relação com a cultura de seu público-alvo. Sandra Paiva (2017, p.10) coloca: "[...] é pertinente relatar que todo produto também tem sua cultura, ou seja, cada mercado a que a embalagem se destina deverá ter um visual condizente com a cultura local". 
Logo, um elemento que tenha relação cultural regional com seus consumidores será notado, mesmo inconscientemente, despertando sensações de familiaridade, conforto e identificação do consumidor com o produto.

\subsection{Impacto econômico e ambiental}

Segundo Calver (2009, p.26), "qualquer solução de embalagem que seja rápida e eficaz prova seu valor rapidamente". É principalmente com base nas possibilidades de medição de eficácia (como os cálculos com dados do ponto de venda) que o design de embalagens é um campo reconhecido pelo marketing e pela economia. Outro quesito importante é que os gastos da produção podem ser diminuídos por meio de uma embalagem - por exemplo, deixando um produto mais leve e fácil de transportar, ou mudando o material de que seu invólucro é feito.

Com a evolução tecnológica e as descobertas científicas crescentes, as possibilidades de materiais para fabricação de embalagens são muitas, de modo que Calver (2009) chega a afirmar que a escolha do material deve ser considerada um pré-requisito para qualquer projeto. Além do impacto econômico dos materiais, porém, é ainda mais importante (para o designer como ser humano consciente e atuante na sociedade) que se considere o aspecto ambiental.

Peltier e Saporta (2009, p.12) dizem que "em menos de um século, a embalagem gerou mais lixo doméstico do que toda a humanidade havia produzido até então". Para os autores foi, no entanto, a visibilidade que as embalagens ganharam que as tornou as "vilãs" da sociedade contemporânea, e as pessoas que as descartam incorretamente têm grande parte da responsabilidade sobre a formação desse ponto de vista. É preciso pesar, porém, as consequências do uso que fazemos das embalagens, já que por um lado seu descarte incorreto pode contribuir para a degradação ambiental, mas por outro sua existência evita desperdícios com as funções de conservação e transporte.

\section{Engenhos Caririenses}

Do século XVI ao XVIII a produção e exportação de cana-de-açúcar constituíram a atividade econômica de maior importância para o Brasil, embora a posição de colônia portuguesa tenha feito com que a maior parte dos lucros fosse dirigida à coroa de Portugal. O açúcar, principal produto final da cana, era consumido em larga escala pelos países europeus e comercializado a preços altos. Foi no nordeste do Brasil que a cana encontrou condições favoráveis, e a região logo se tornou o polo do açúcar brasileiro, com plantações se iniciando no litoral e depois rumando para o interior (SILVA, 2008).

De início os currais de gado foram a atividade-base do sertão, povoando o interior. A agricultura, que havia surgido como complemento, tornou-se uma alternativa à pecuária. Ao sul do Ceará povoou-se a região conhecida como Cariris-Novos, hoje denominada Cariri. De acordo com Maria Yacê Carleial Feijó de Sá (2007), as condições peculiares do solo e clima foram essenciais para a ocupação caririense: solo fértil, distribuição hidrográfica favorável à irrigação e formação de brejos teriam sido características que atraíram os agricultores, e logo foram percebidas como ideais para o plantio da cana-de-açúcar, que rapidamente se tornou a base da economia regional.

Para José de Figueiredo Filho (2010), é no cultivo da cana e seus engenhos que mora a importância da região do Cariri - e, embora desde a época em que seu livro foi escrito (1958) o Cariri tenha se expandido social e economicamente, destacando-se também em outros aspectos, 
seus produtos derivados da cana ainda apresentam destaque no mercado por questões de qualidade e tradição. Dentre tais derivados, podemos mencionar principalmente rapadura, batida, mel, alfenim e aguardente de cana.

\title{
3.1 Rapadura
}

A rapadura é um doce sólido de cor amarronzada, surgido da raspagem dos tachos de açúcar. Nasceu nas Ilhas Canárias, no século XVI, mas foi adotada no Brasil como alimento para os escravos e depois tornou-se alimento indispensável para nordestinos, que também labutavam duramente e precisavam da energia fornecida por seu alto valor calórico (SAKAI, 20??). Gilberto Freyre (1969, apud GONÇALVES, 2011, p.40) chama a rapadura de "fator medicinal de resistência do homem sertanejo".

De acordo com Figueiredo Filho (2010), a rapadura no Cariri era produzida com base nas plantações de cana não apenas dos senhores de engenho, mas também nos menores plantios, pertencentes aos trabalhadores de engenho e aos pequenos lavradores. A safra dos mais humildes, porém, era destinada quase completamente à venda, e não recebia o devido valor na hora do pagamento. Além disso, o agricultor de menores posses estava "preso" ao engenho como se fosse funcionário, uma vez que sua cana era moída no engenho mais próximo e dependia da água do mesmo para irrigar suas plantações.

"Está a rapadura intimamente vinculada à vida sertaneja" (Id. Ibid., p.57). É possível observar, nos registros históricos, que tais vínculos (tanto com a rapadura quanto com os engenhos que a produziam) não se restringiam ao aspecto alimentar e econômico, mas também ao emocional do homem caririense.

\begin{abstract}
De maio para junho, o burro inquieta-se. Fica como a sentir o cheiro do engenho [...], ao retomarem a estrada, saltam de alegria. E saem em disparada para logo alcançarem o olho de cana, a baba e o cambiteiro [...]. O homem também é assim. Quando sai do Cariri, não pode esquecer o engenho. (FIGUEIREDO FILHO, 2010, p.39)
\end{abstract}

\subsubsection{Produção da rapadura}

Segundo Antônio Sampaio Júnior ${ }^{1}$, a primeira etapa de produção da rapadura seria a moagem. No entanto, SAKAI (20??) pontua que um transporte rápido do ponto de corte da cana até o local de moagem é essencial para uma boa qualidade da rapadura, sendo a demora uma das principais causas de perda dessa qualidade. Sendo assim, podemos considerar o corte e o transporte da cana-de-açúcar como os primeiros passos da fabricação da rapadura.

Ainda segundo SAKAI (ibidem), o caldo de cana que vem do processo de moagem segue para decantação, onde o caldo se torna livre de impurezas. Esse é o momento também da clarificação, quando se adiciona o hidrossulfito (ditionito) de sódio, que alguns produtores utilizam para tornar a cor da rapadura mais clara e, assim, melhorar sua aparência.

Depois disso se iniciam as etapas de fervura do caldo (também chamadas de concentração). Antônio Sampaio Júnior afirma que há cinco pontos de fervura do caldo. 0 primeiro e o segundo servem para que quaisquer impurezas resistentes ao processo de decantação sejam eliminadas. O terceiro é para adição de temperos, caso se deseje adicionar algum. O quarto, para obter o ponto de mel. E o quinto, para atingir o ponto da batida e da

\footnotetext{
${ }^{1}$ Filho do Sr. Antônio Sampaio (dono do Engenho Padre Cícero), em entrevista concedida a Ingrid Nogueira Freitas nas dependências do referido engenho, no dia 21 de abril de 2017.
}

13 Congresso Brasileiro de Pesquisa e Desenvolvimento em Design, Joinville (SC) 
rapadura, que se diferenciam pelo tempo de fervura nessa etapa. As fervuras podem acontecer no mesmo tacho, mas há engenhos nos quais ocorrem em tachos diferentes.

Após as fervuras acontece o batimento, quando o caldo é mexido até atingir o ponto para a moldagem. No processo de moldagem é colocado nas fôrmas (algumas de madeira, outras de tijolos) e, depois de resfriado, é desenformado.

\subsection{Barbalha: Apogeu e Queda dos Engenhos do Cariri}

O município de Barbalha, que é parte do Cariri cearense (a $575 \mathrm{~km}$ da capital do estado, Fortaleza), adotou em suas origens a agricultura canavieira como principal atividade, possuindo então mais de uma centena de engenhos que funcionavam a pleno vapor e produziam não apenas rapadura, mas também demais derivados da cana. Essa produção rendeu à cidade os títulos de "Capital Nacional da Rapadura" e de "Terra dos Verdes Canaviais", o qual perdura mesmo com a extinção de grande parte dos engenhos que um dia movimentaram sua economia e motivaram as enormes plantações de cana-de-açúcar que podiam ser vistas logo na entrada da cidade e que honravam tal apelido recebido.

Napoleão Tavares Neves (apud SILVA NETO, 2009) afirmou que, no auge da produção dos engenhos, a cidade de Barbalha chegava a produzir 30 milhões de unidades de rapadura: 300 mil cargas - informação que Figueiredo Filho (2010) também forneceu.

O dono do engenho Padre Cícero (que é o engenho contemplado neste trabalho), sr. Antônio Sampaio, respondeu a uma entrevista publicada no site Diário do Cariri, na qual fala um pouco sobre como eram os engenhos barbalhenses em 1978, quando o Engenho Padre Cícero se iniciou: tudo era feito em madeira, desde as moendas às colunas de sustentação do prédio. A natureza era bastante prejudicada no processo e o maquinário era pouco desenvolvido, sendo a força humana ainda muito utilizada na produção - apesar disso, havia lucro (embora pouco) ao fim da moagem.

“Hoje, as despesas são altíssimas, e o que se ganha é pra apenas manter o engenho funcionando, essa diferença fechou as portas de muitos engenhos na região", disse Antônio Sampaio na mesma entrevista.

De acordo com Silva Neto (2009), havia quase 200 engenhos funcionando no Cariri durante a década de 60. Em 2009, restavam 10. Desses 10, apenas 4 ainda operavam na região. 8 anos depois, em Barbalha, se ninguém perguntar especificamente pelo assunto, provavelmente não ouvirá falar dos engenhos que estruturaram sua economia e sociedade.

As causas da decadência foram muitas. Figueiredo Filho (2010) afirma ter indagado ao sr. Luís Gonzaga de Melo o que estaria atrapalhando a produção de rapadura no Cariri. À época, o homem teria respondido que o problema maior se concentrava nos impostos cobrados pelo governo estadual sobre as vendas à vista. O governo não ofereceria assistência aos agricultores da cana. Falta de mercado, cheques sem fundos nos pagamentos e grande fiscalização do Ministério do Trabalho são fatores também apontados como razão da queda dos engenhos, de acordo com Everardo Sampaio e Antônio Sampaio (SILVA NETO, 2009).

Outro problema mencionado por Figueiredo Filho (2010) e que pudemos constatar recentemente ainda existir, embora em um contexto diferente, foi a fuga de mão de obra. Em abril de 2017 centenas de trabalhadores entre os 20 e os 30 anos rumaram para Minas Gerais em busca de emprego como cortadores de cana. 
Figura 1 - Fuga da mão-de-obra

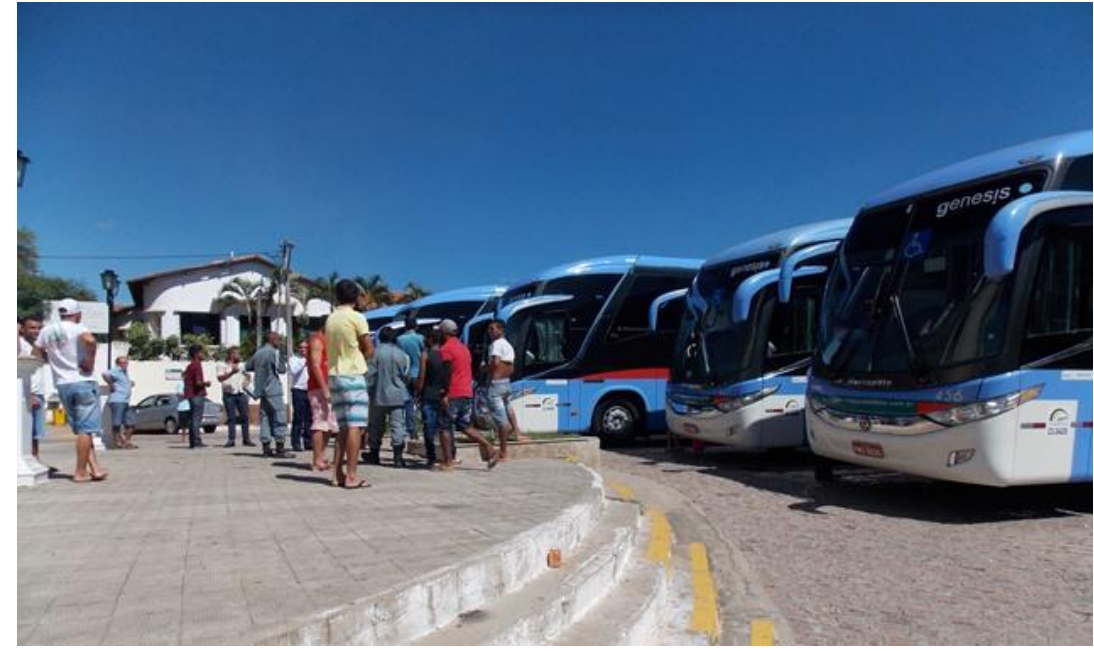

Fonte: <https://goo.gl/8dhsJD> (2017)

A mão de obra que se evade é, atualmente, de cortadores de cana, embora Gonçalves (2011) mencione uma dissolução das divisões de trabalho nos engenhos, de modo que a pessoa que coloca o caldo no decantador pode, em outro momento, estar desenformando a rapadura. Embora todos os trabalhadores envolvidos no processo sejam importantes, porém, o profissional que obtinha maior destaque no processo era o mestre de rapadura em cada engenho.

O trabalhador mais compenetrado do engenho é o mestre da rapadura. Há deles, afamadíssimos. Fora do Cariri, não há ninguém que possa igualá-lo na arte de cozinhar e dar essa consistência fixa à rapadura caririense, de tanta fama e de tanta nomeada. [...] Onde, porém, o mestre se torna mais imponente, é quando mexe o mel na gamela." (FIGUEIREDO FILHO, 2010, p.41)

Ao que diz Gonçalves (2011, p.66): “o mestre de rapadura caracterizado por José de Figueiredo Filho há mais de meio século em nada difere do atual trabalhador responsável pela garantia de qualidade do produto de cada engenho". Porém, assim como pouco ou nada se ouve falar sobre os engenhos nas ruas da cidade, também desapareceu das conversas o mestre de rapadura, um dos protagonistas do processo produtivo das casas açucareiras. Eis mais uma marca da decadência dos engenhos.

Existem, porém, sobreviventes. Embora não tenha sido possível quantificar os engenhos que ainda funcionam plenamente na cidade, segundo a Secretaria de Agricultura de Barbalha (apud LEITE; VIEIRA; SILVA, 2014), em 2012 eram apenas onze. Em 2014, de acordo com o Diário do Nordeste (2014), esse número havia diminuído para quatro. O Engenho Padre Cícero é um dos que permanecem em atividade - segundo Antônio Sampaio Júnior, os planos são para modernizálo e, assim, mantê-lo em atividade enquanto for possível.

\section{Projeto}

\subsection{Primeira Etapa: Caso}

\subsubsection{Briefing}

O briefing foi realizado nas dependências do engenho Padre Cícero, no dia 21 de Abril de 2017, por meio de entrevista presencial com Antônio Sampaio Júnior e com Antônia Quesado 
Luiza, respectivamente filho e esposa do proprietário do engenho, o sr. Antônio Sampaio, que infelizmente não pôde estar presente.

Durante a entrevista, que foi baseada em um questionário previamente elaborado, descobrimos que atualmente os produtos fabricados pelo engenho são: rapadura, mel, batida, cachaça e raizada, com variações nos ingredientes, peso e forma de embalo. As garrafas nas quais se vendem o mel, a cachaça e a raizada têm capacidade de $1 \mathrm{~L}$, e são compradas de um fornecedor que vende garrafas reutilizadas. As rapaduras, batidas e suas variações estão na tabela a seguir:

Tabela 1 - Variações das rapaduras e batidas do Engenho Padre Cícero

Produto

Peso

\begin{tabular}{cc}
\hline Tablete (batida na palha) & $250 \mathrm{~g}$ \\
\hline Tablete comum - batida & $300 \mathrm{~g}$ \\
\hline Tablete comum - rapadura & $350 \mathrm{~g}$ \\
\hline Drops de rapadura & $450 \mathrm{~g}$ \\
\hline Bolo (batida na palha) & $1 \mathrm{~kg}$ \\
\hline Mato-véio (rapadura grande) & $1,5 \mathrm{~kg}$
\end{tabular}

Fonte: a autora, com base no briefing

Embora o engenho terceirize seus produtos para exportação em outros estados do Brasil e também receba alunos levados por escolas para aulas de campo, os entrevistados no briefing definem seus principais clientes como os romeiros; essa informação condiz com o que identificamos como público-alvo desse projeto.

A produção atual é de 6000 unidades - cerca de $2400 \mathrm{~kg}$ de rapadura e batida por dia em seu período de funcionamento constante (de setembro a fevereiro do ano seguinte, propositadamente combinando com as datas de maior movimentação na romaria de Juazeiro do Norte). Nesse período uma grande demanda, se já adiantada pela moagem prévia da cana, pode ficar pronta em 3 ou 4 dias. No período de menor movimento, a produção segue o sistema just in time, no qual só é produzido o que for encomendado, a fim de evitar que os produtos se deteriorem na armazenagem e de reduzir gastos.

A cana-de-açúcar, principal matéria-prima da rapadura e da batida, advém de uma plantação que também pertence ao dono do engenho, enquanto ingredientes secundários (tais como coco, castanha e amendoim), devido aos preços, são comprados em Fortaleza.

Os produtos que serão exportados são armazenados em um galpão, e a parte que será vendida aos turistas fica exposta em uma pequena varanda com balcões que funciona como uma lojinha. Essa área de atendimento, o galpão e uma pequena cozinha foram melhorias construídas "para bem atender os romeiros de meu Padim Pade Ciço", afirma Antônio Sampaio na entrevista concedida a Silva Neto (2009). 
Figura 2 - Lojinha do Engenho Padre Cícero

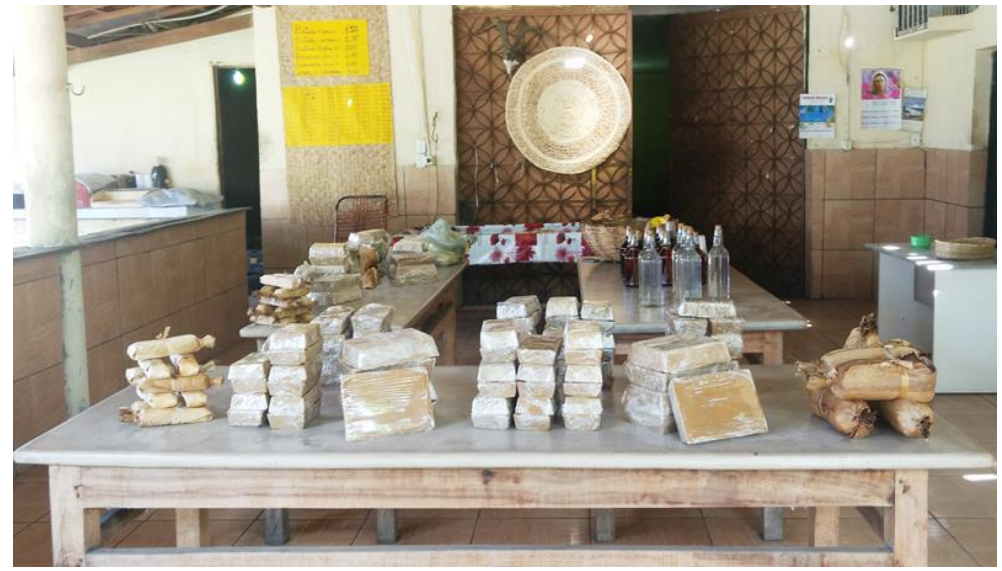

Fonte: a autora

O filme plástico e a palha que hoje embalam as rapaduras e batidas são adicionados aos produtos por funcionários do engenho. Não há pessoas específicas para a tarefa, e o local onde costuma acontecer esse embalo é um canto do grande galpão no qual as rapaduras e batidas são feitas. Em uma comparação de imagens feitas por nós e imagens obtidas em 2010 pelo repórter Alfredo Bokel, é possível observar que, em sete anos de diferença, esse local permanece o mesmo.

Figura 3 - Local onde os produtos são embalados

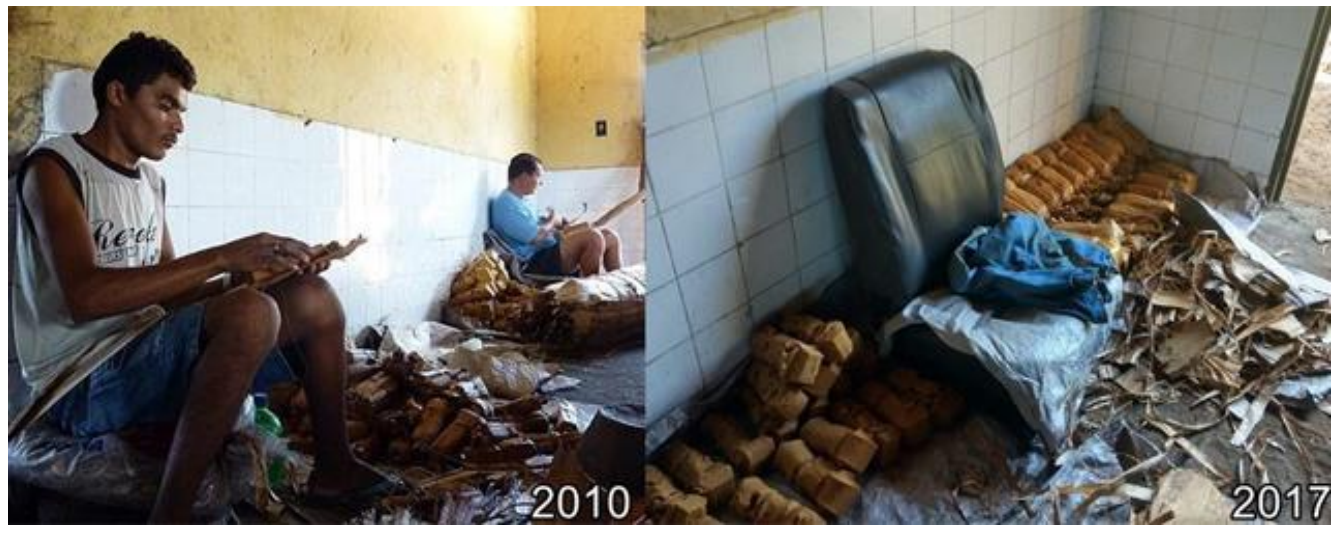

Fonte: <https://goo.gl/hWpXtb> (imagem da esquerda), e a autora (à direita)

\subsubsection{Público-alvo}

O público-alvo do Engenho Padre Cícero consiste em turistas religiosos que visitam Juazeiro em épocas de romaria. Embora haja vendedores de outros estados que compram os produtos do engenho, seu propósito é terceirizar a mercadoria, de modo que os produtos que podem manifestar sua identidade e levar sua marca são aqueles vendidos diretamente ao público - no caso, os romeiros.

Enquanto público-alvo, os romeiros não têm características padronizadas: de todas as idades, vêm de diversas partes do país (embora haja uma predominância de peregrinos da região nordeste) e pertencem às mais variadas classes sociais - de acordo com a Revista Cariri, são agricultores, assistentes de saúde, advogados e políticos, vindos de pau-de-arara, de ônibus ou em 
carros próprios, hospedando-se em ranchos de romeiros, em pousadas ou em hotéis renomados, seguindo ou não tradições familiares. O único ponto em comum seria a fé.

Os locais mais visitados pelos romeiros em suas peregrinações ficam em Juazeiro. No entanto, as cidades imediatamente vizinhas a Juazeiro, Crato e Barbalha, também recebem visitas. No caso de Barbalha, está aí a razão dos romeiros serem o público-alvo do Engenho Padre Cícero: é ali que são recebidos, para conhecer a produção e provar da rapadura, do mel e dos demais produtos derivados da cana-de-açúcar caririense. Segundo Leite, Vieira e Silva (2015), em 2012 o engenho Padre Cícero recebia, em período de produção constante, aproximadamente 90 ônibus de romeiros.

\subsection{Segunda Etapa: Problema}

\subsubsection{Problema Central}

O problema central deste projeto envolve, com base em seu público-alvo, questões formais e de transporte: as atuais embalagens utilizadas pelo engenho não atraem o consumidor, carecendo de apelo estético, identificação e informações sobre o produto; além disso, não são propícias a serem carregadas pelo usuário, parte de um público passante que costuma depender de meios de locomoção coletivos.

\subsubsection{Subproblemas}

Função formal: a estética é essencial para a atração que o produto exerce sobre o cliente. No entanto, a forma neste trabalho também trata da funcionalidade no transporte, considerando o tipo de consumidor e seu ponto de venda.

Higiene: as embalagens já existentes podem ser divididas em três grandes grupos: invólucros plásticos (para a rapadura e a batida comuns), saco plástico (para os drops de rapadura) e palha (para a batida em palha).

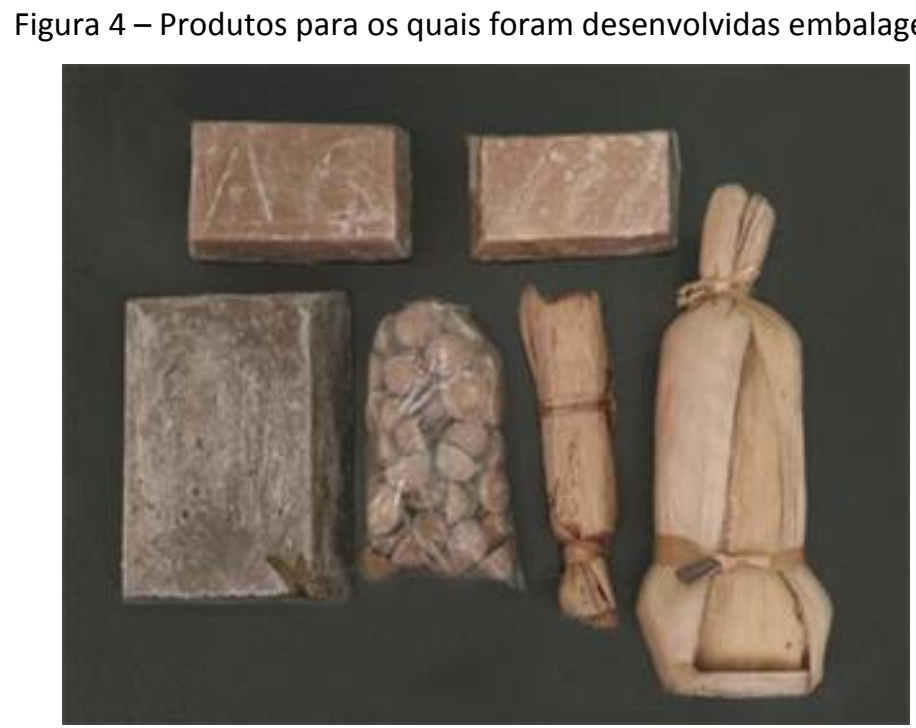

Fonte: a autora 
Função simbólica: as embalagens atuais para batidas e rapaduras, embora tradicionais, não cumprem as funções determinadas pelos estudiosos do Design de Embalagens, de modo que acabam por não aproveitar todo o potencial do valor cultural desses produtos.

\subsection{Terceira Etapa: Hipótese}

\subsubsection{Ideias}

Tendo em mente as funções mencionadas pelos autores que estudamos e as características do engenho (tradição), dos produtos (peso, forma, armazenamento, valor cultural) e de seu público-alvo (viajantes), foi estabelecido que as embalagens resultantes desse trabalho deveriam:

Quanto à estrutura:

- Ser resistentes;

- Auxiliar na questão higiênica;

- Facilitar o transporte;

- Permitir exposição no ponto de venda;

- Apresentar facilidade na fabricação, montagem e uso;

- Causar o mínimo possível de danos ambientais;

- Se adequar à realidade financeira e local do Engenho Padre Cícero e público-alvo;

Quanto à estética:

- Remeter à tradição e ao aspecto saudável da produção artesanal

- Trazer inovação e elegância

Para as rapaduras e o tipo mais básico de batida aproveitamos o formato de trapézio das laterais, tornando a estrutura da embalagem um tronco de pirâmide. Adicionamos alças para ajudar no transporte. Para os drops de rapadura adaptamos a ideia de uma sacola de papel com características que proporcionam mais segurança e praticidade. Para as batidas embaladas em palha, dada a função simbólica do material, incluímos um pequeno livreto/tag para ser o rótulo, e no interior um saco plástico para evitar contato direto da palha com o produto alimentício.

Por questões de higiene e também considerando que não significaria um aumento de gastos porque o sistema já é adotado, preferimos manter no projeto os filmes plásticos que o engenho já aplica às rapaduras em formato comum, assim como os sacos plásticos nos quais os drops são vendidos atualmente. Desta forma, as caixas, a sacola e o livreto que criamos neste trabalho serão adições ao que já é feito para embalar os produtos.

\subsubsection{Testes de Planificação, Material e Resistência}

Quando já havia uma ideia geral de que aspectos estruturais e estéticos se pretendia seguir, pesamos e medimos os exemplares de produtos adquiridos no engenho. Então iniciamos os esboços, rascunhados à mão, de caixas em formato de trapézio. Os desenhos foram planificações dessa forma geométrica, analisando possíveis posições de alças para facilitar o transporte, definindo a maneira como as embalagens seriam abertas e lacradas, e considerando como o formato impactaria na resistência ao peso de cada produto do engenho.

Com os esboços prontos e as melhores ideias selecionadas, incluímos uma rodada de testes a fim de conferir se o imaginado seria funcional na prática. Nessa fase utilizamos papel sulfite comum e colorido, papel duplex, papel paraná e papel kraft, experimentando com suas diferentes 
texturas e resistências. Ao todo, foram feitos 15 testes diferentes com caixas e sacolas planificadas e montadas manualmente.

Enquanto os testes em papel sulfite permitiam checar a planificação e encaixes, as tentativas em papéis de maior resistência determinavam se aquele material poderia ser utilizado nos protótipos e produtos finais, suportando seu peso e o formato. Para tanto usamos a rapadura Mato-Véio, que é a mais pesada $(1,5 \mathrm{~kg})$, já que a resistência de sua embalagem significaria que o material também aguentaria o peso e o volume dos produtos mais leves. Também incluímos os drops de rapadura em algumas dessas provas.

Após diversos testes que resultaram em rasgos, dobras ou inclinações indesejadas devido ao peso da rapadura, repetimos os esboços e provas, uma vez que a metodologia UAM é cíclica. Por fim obtivemos um modelo resistente e satisfatório com uso de papel kraft. Os ângulos de fechamento da embalagem foram posteriormente ajustados com o uso do programa de modelagem 3D chamado Rhinoceros 4.0.

Para as tags/livretos que acompanhariam as batidas em palha, imaginamos um formato prático de apenas uma dobra, e tomamos por base a batida em tablete pequeno. Também nos utilizamos do tamanho mínimo de tabela nutricional determinado pela ABRE (Associação Brasileira de Embalagem) e da legibilidade das informações a serem adicionadas no livreto. O cordão escolhido para prender a tag às embalagens foi o cordão sisal, que é similar a uma corda e lembra a própria palha, conferindo harmonia e mantendo a identidade visual da embalagem.

\subsubsection{Hipótese Final: Identidade Visual}

Foi definido que a identidade visual se utilizaria de elementos de embalagens "vintage", de modo a remeter, mesmo em níveis subconscientes, a produtos tradicionais. Optamos por:

- Ilustrações, permitindo inúmeras possibilidades e lembrando a época em que as fotografias não tinham qualidade suficiente para estarem em rótulos;

- Elementos relacionados ao vegetal componente do produto, como as cervejas que traziam ilustrações de trigo em seus rótulos;

- Tipografia em destaque, ladeada por detalhes tais como uma forma geométrica ou um laço.

Foi feita uma síntese da estrutura da cana-de-açúcar, que rotacionada gerou uma estampa.

Para o nome do engenho, buscamos tipografias que pudessem remeter novamente aos rótulos vintage. Após testes em mockups, optamos pela tipografia Rita Smith para as palavras "rapadura do engenho" e pela tipografia Título para o nome "Padre Cícero", conferindo ao nome do padre um maior destaque a fim de ressaltar a fé do romeiro.

Com base na diversidade do público viajante decidimos adicionar as palavras "rapadura do engenho Padre Cícero" em todos os rótulos, já que peregrinos vindos de outras regiões podem não ter conhecimento prévio sobre o produto, não compreendendo que a batida é uma variação do ponto da rapadura, embora mantenha seus ingredientes e modo de preparo.

Quanto à estampa, sua aplicação em uma área extensa da embalagem, mesmo que apenas na face frontal, utilizaria muita tinta, tornando o processo mais caro e o dano ao meio-ambiente maior. Usamos, portanto, uma faixa vertical para delimitá-la: após alguns testes com mockups, 
descobrimos que a posição vertical da faixa permitia melhor adequação aos formatos de embalagem propostos.

\subsection{Quarta Etapa: Projeto}

Os rótulos frontais possuem, de acordo com o que é determinado pela legislação brasileira sobre embalagens, a marca dos produtos, sua denominação de venda e conteúdo líquido.

Os rótulos traseiros trazem, de obrigatório: tabela nutricional, espaço para informações de validade e lote (que, por variarem de acordo com a produção, devem ser adicionados pelo próprio engenho por meio de carimbos), lista de ingredientes, declaração de ausência de glúten, informações sobre a empresa (incluso o CNPJ) e os dizeres "indústria brasileira". Como informação opcional adicionamos um pequeno texto para valorizar ainda mais o aspecto tradicional e fazer com que o Cariri seja reconhecido nos demais lugares para os quais os romeiros possam levar os produtos. O texto é o seguinte: "Esse produto foi feito na Terra dos Verdes Canaviais, Barbalha, com cana-de-açúcar natural da região, e sua produção é tradicional dos engenhos caririenses".

\subsubsection{Protótipos}

Foram escolhidos três modelos para protótipo, com base na divisão das embalagens em três grandes grupos: a sacola (drops), as caixas (da Mato-Véio, da rapadura tablete $350 \mathrm{~g}$ e da batida tablete $300 \mathrm{~g}$ ) e as tags (da batida na palha e da batida Bolo). Um modelo de cada foi selecionado para produção.

Os protótipos foram feitos no papel oficial escolhido para a produção, que é o kraft $320 \mathrm{gr}$, e reproduzidos em tamanho real. No entanto, uma vez que a impressão indicada oficialmente (a offset) só é feita em larga escala e seria dispendiosa, optamos por outro meio: um adesivo transparente. Para os modelos não produzidos fisicamente foram feitas renderizações utilizando o software Rhinoceros 4.0.

Figura 5 - Protótipos de três das embalagens desenvolvidas

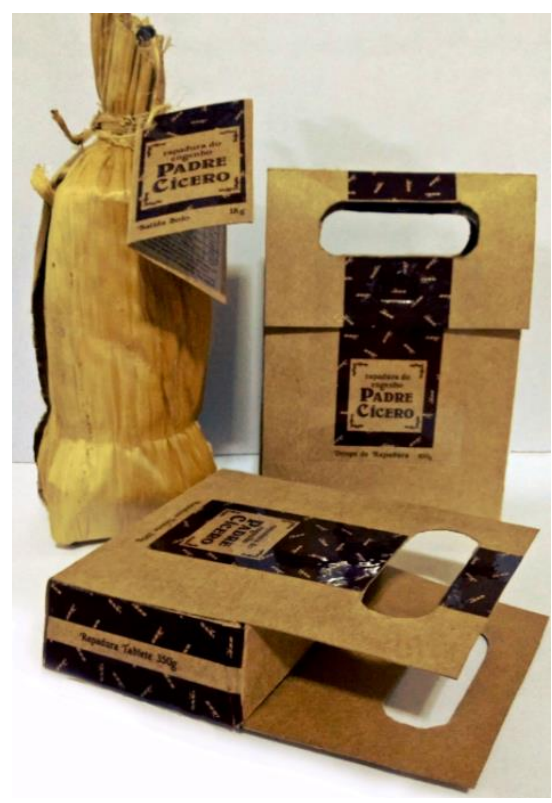

Fonte: a autora 


\subsubsection{Impactos Ambientais}

Neste trabalho tentamos amenizar os danos ao meio-ambiente, mesmo com limitações orçamentárias e de técnicas disponíveis no na região (para que seja possível que o engenho mande fazer as embalagens nos arredores de Barbalha). Fizemo-lo por meio de:

- Uso do mínimo possível de materiais diferentes, facilitando a reciclagem;

- Uso do papel kraft em sua cor natural, diminuindo o gasto de tinta tanto na produção do papel em si quanto na impressão;

- Não adição de acabamentos em hot stamping, verniz, etc;

- Planificação planejada, por meio de ângulos e abas, para diminuir o uso de papel;

- Escolha de cor única para todo o trabalho de impressão offset;

- Uso do sistema de faca de corte e vinco para a pré-montagem (a faca pode ser reutilizada diversas vezes, se lâmina for amolada com frequência).

\section{Conclusão}

Ao analisar os resultados, percebemos que atingimos os objetivos que nos propusemos a alcançar: desenvolvemos a linha de embalagens dentro do que foi determinado, atribuindo-Ihes características que conferem maior valor estético e simbólico aos produtos, e durante o processo registramos a história e o funcionamento do engenho que os fabrica.

Concluímos também que a criação de uma memória para a posteridade foi além do esperado, porque a rapadura em si é um registro "vivo": dentre os derivados da cana-de-açúcar, é a mais forte representante do povo sertanejo, tendo sido base não apenas econômica, mas também alimentícia para os fortes que trabalharam de sol a sol para construir o Cariri que hoje habitamos. Ressignificá-la é, portanto, contribuir para que permaneça existindo uma peça-chave para a cultura de nosso povo.

Este trabalho constitui, em análise final, um lembrete de que o Design, como ferramenta de transformação social, tem o poder (e o dever, do ponto de vista ético/emocional) de contribuir para a manutenção de nossa história, seja registrando o passado e o presente para que se possa lembrá-los no futuro, seja ressignificando algo importante que não é mais tão valorizado.

\section{Referências}

ANTUÑANO, J.S.; GUTIÉRREZ, M.L., et al. MODELO GENERAL DEL PROCESO DE DISEÑO CYAD-UAM AZCAPOTZALCO. In:__. Contra un Diseño Dependiente: un modelo para la autodeterminación nacional. Colección CyAD Universidad Autónoma Metropolitana. México: [s.n.], 1992. Cap. 2.3, p. 69-85.

APESCE - Associação Pernambucana de Shopping Centers, Pesquisa de mercado. Disponível em: < http://apesce.com.br/noticias/?id=754>. Acesso em: 22 de abril de 2017.

CALVER, Giles. O que é design de embalagens?. Porto Alegre: Bookman, 2009.

DIÁRIO DO NORDESTE. Escola em Barbalha busca o resgate da cultura canavieira. Disponível em: <http://diariodonordeste.verdesmares.com.br/suplementos/cariri-regional/escola-em-barbalhabusca-o-resgate-da-cultura-canavieira-1.998074>. Acesso em: 20 de junho de 2017.

FIGUEIREDO FILHO, José de. Engenhos de rapadura do cariri. Fortaleza: Editora da Universidade Federal do Ceará - UFC, 2010. 
FREITAS, Ingrid Nogueira. Desenvolvimento de embalagens para produtos do Engenho Padre Cícero. 2017. Projeto de Produto (Graduação Tecnológica em Design de Produto) - Universidade Federal do Cariri, Juazeiro do Norte, Ceará, 2017.

GONÇALVES, Naudiney de Castro. "O fogo não está morto": engenhos de rapadura do Cariri cearense como uma referência cultural na perspectiva das políticas públicas do último quartel do século XX. 2011. 83 f. Dissertação (Mestrado em História) - Universidade Federal de Minas Gerais, Faculdade de Filosofia e Ciências Humanas, Belo Horizonte, 2011. Disponível em: <http://www.bibliotecadigital.ufmg.br/dspace/bitstream/handle/1843/VGRO-

8NEG37/_disserta_o_de_mestrado__naudiney_pdf?sequence=1>. Acesso em: 16 de março de 2017.

LEITE, Marcelo Eduardo; VIEIRA, Leylianne Alves; SILVA, Carla Adelina Craveiro. Tradição e resistência no Cariri cearense: Uma pesquisa Fotoetnográfica no Engenho Padre Cícero, Barbalha/CE. Revista NAU Social, [S.L], v. 5, n. 9, p. 09-21, nov 2014./abr. 2015.

NEGRÃO, Celso; CAMARGO, Eleida. Design de embalagem: do marketing à produção. São Paulo: Novatec, 2008.

NETO, Silva. Cana-de-açúcar no Cariri: engenhos resistem à crise. Disponível em: < http://www.diariodocariri.com/noticias/cariri/615/cana-de-acucar-no-cariri-engenhos-resistem-acrise.html>. Acesso em: 30 de junho de 2017.

NETO, Silva. Romeiros em festa no Engenho Padre Cícero. Disponível em: < http://www.diariodocariri.com/noticias/barbalha/2763/romeiros-em-festa-no-engenho-padrecicero.html>. Acesso em: 30 de junho de 2017.

NORMAN, Donald. Design emocional: Por que adoramos (ou detestamos) os objetos do dia-a-dia. Rio de Janeiro: Rocco, 2008.

PAIVA, Sandra. A embalagem como forma de comunicação e expressão. 2008. Monografia (Bacharelado em Comunicação Social) - Universidade Salgado de Oliveira, Juiz de Fora, Minas Gerais, 2008. Disponível em: < http://www.webartigos.com/articles/8848/1/A-Embalagem-ComoForma-De-Comunicacao-E-Expressao/pagina1.html\#ixzz0y45hT6zh>. Acesso em: 20 de abril de 2017.

PELTIER, Fabrice; SAPORTA, Henri. Design sustentável: caminhos virtuosos. São Paulo: Editora Senac, 2009.

REVISTA CARIRI. Juazeiro do Norte: Editora 309, n. 28, 2016.

SÁ, Maria Yacê Carleial Feijó de. Os homens que faziam o Tupinambá moer: Experiência e Trabalho em Engenhos de Rapadura no Cariri (1945 - 1980). Dissertação (Mestrado em História Social) - Universidade Federal do Ceará, Fortaleza, Ceará, 2007. Disponível em: < http://livros01.livrosgratis.com.br/cp124916.pdf>. Acesso em: 28 de abril de 2017.

SAKAI, Rogério Haruo. Rapadura. Disponível em: < http://www.agencia.cnptia.embrapa.br/gestor/cana-deacucar/arvore/CONT000fjighhp202wyiv80sq98yqyvgmia8.html>. Acesso em: 29 de abril de 2017.

SILVA, Bruno Izaías da. Ciclo da cana-de-açúcar. Disponível em:< http://www.infoescola.com/historia/ciclo-da-cana-de-acucar/> . Acesso em: 29 de abril de 2017. 